\title{
CONCEITUANDO O TRABALHO, O VISÍVEL E O INVISÍVEL
}

\author{
CONCEPTUALIZING THE WORK, THE VISIBLE AND INVISIBLE
}

Yves Schwartz ${ }^{1}$

Resumo Neste artigo discutimos, na perspectiva da ergologia, o conceito de trabalho. Situamos as definições dele ao longo da história por diferentes correntes de pensamento e polemizamos sobre o caráter inédito, invisível e visível do trabalho. O que ele pressupõe e o que ele permite inferir em termos de investimento humano pessoal e coletivo. O que ele revela em termos de continuidades de modos de fazer e o que ele omite em termos de saberes investidos. Procuramos retrabalhar a noção de trabalho, tentando explicar os impasses evocados. Ao final, sugerimos como esta reapreciação da noção de trabalho poderia reinterrogar também o trabalho do historiador.

Palavras-chave ergologia; atividade de trabalho; história.
Abstract This paper discusses, from the perspective of ergology, the concept of work. We place the definitions of it throughout history by different currents of thought and debate about the unprecedented nature, invisible and visible of labor. What it entails and what it allows us to infer in terms of collective and personal human investment. What it reveals in terms of continuity of ways of doing and what it omits in terms of knowledge invested. We seek to rework the notion of work, trying to explain the dilemmas evoked. Finally, we suggest how this review of the concept of work could also interrogate the historian's work.

Keywords ergology; work activity; history. 
Há alguns anos, um congresso de historiadores 2 propôs como tema "O trabalho e os homens". Na justificativa de sua realização, dava provas de lucidez e de prudência salutares ao afirmar "o trabalho como categoria cultural" a partir de uma evidência: "em todas as sociedades, quaisquer que sejam os lugares ou as épocas, os homens e as mulheres trabalham, ou seja, envolvem seus corpos em uma atividade socialmente programada que visa a produzir os meios materiais de suas existências". E, ao mesmo tempo, porque "todo o mundo não partilha a mesma concepção do trabalho". O congresso se propunha a acolher "tanto declinações eruditas quanto ordinárias de situações qualificadas de "trabalho'" (Congrés Annuel du Centre des Travaux Historiques et Scientifiques, 2002).

O 'trabalho' é ao mesmo tempo uma evidência viva e uma noção que escapa a toda definição simples e unívoca. É sem dúvida nesse 'e' que une 'o trabalho' e 'os homens' que repousa provavelmente a fonte desse caráter enigmático, gerador de paradoxos, e que permite a questão: o que está comprometido - do homem - no trabalho?

O propósito da contribuição deste artigo visa a autenticar essa dificuldade e a situar os desafios não negligenciáveis para os estudos históricos, a assumir a ideia de que o trabalho é uma realidade enigmática, e que uma definição clara do trabalho será sempre um problema.

Para ser mais preciso sobre este ' $\mathrm{e}$ ', buscar a 'atividade de trabalho' por detrás do 'trabalho' permite, do nosso ponto de vista, compreender por que ele não é um parâmetro, como outro qualquer, do processo histórico, mas é a própria base do que 'faz a história' para os homens. E isso sem reproduzir aqui teorizações ilustres que fizeram do trabalho a própria matriz da história, seja como sucessão dos diversos 'momentos' do conceito do trabalho (Hegel), ou como lugar do desenvolvimento das contradições entre relações de produção e forças produtivas (materialismo histórico). Isso não significa que esses grandes sistemas conceituais não sejam eminentemente formadores do nosso olhar sobre o trabalho e os homens, mas talvez lhes faltassem - para o primeiro mais nitidamente do que para o segundo - entrar verdadeiramente no trabalho pela 'atividade' de trabalho.

Examinaremos, primeiro, três impasses significativos, ilustrando os reveses do pensamento conceitual ao delimitar um objeto que lhe é, entretanto, essencial. Em seguida, procuraremos retrabalhar a noção de trabalho, tentando explicar, por causa de suas dimensões invisíveis, os impasses evocados. Em uma terceira etapa, nos permitiremos, imprudentemente, sugerir como esta reapreciação da noção de trabalho poderia eventualmente reinterrogar, a partir de alguns pontos tópicos, o trabalho do historiador. 


\section{Alguns impasses significativos}

\section{O primeiro impasse}

O primeiro impasse é relativo à data do 'nascimento' do trabalho. Sem dúvida, a formulação da própria questão é extremamente criticável, como o é em geral a ideia de 'mutação': como se, em alguns aspectos de seus comportamentos vitais e sociais, a humanidade pudesse cortar os fios de uma memória patrimonial, inscrita em nossos corpos vivos e operantes. Felizmente, não são os historiadores a quem é necessário convencer a pesquisar em nossas heranças as potencialidades da emergência do novo.

Mas a constatação do que encontramos na literatura científica como um "triplo nascimento" do trabalho - em que o mesmo termo designa três momentos e fenômenos muito distintos, sem que a compreensão seja em cada caso fundamentalmente afetada pela heterogeneidade do que designa a palavra - manifesta bem a ambiguidade do conceito de trabalho.

Assim, parece lógico datar o nascimento do trabalho a partir da fabricação das primeiras ferramentas: fabricação amplamente padronizada de objetos mediatizando a relação de uma população com seu meio de existência, no eixo de uma transformação, culturalmente transmitida, das normas de satisfação da vida.

Sem dúvida hoje não há provas de que essa indústria seja a marca exclusiva de nosso mais distante ancestral humano, o homo habilis. Os 'ateliês' de pedras entalhadas descobertos no Kênia, aproximadamente há 2,5 milhões de anos, não podem ser atribuídos, com certeza, ao homo habilis mais do que a outros hominídeos (Roche e Tiercelin, 1977; Roche, 2002; Semaw, 1997). Mas, uma vez admitida essa possível transferência de imputação, o fato de que se possa falar de 'manufatura', de métodos relativamente estereotipados e pensados de forma pragmática incita, mesmo que a um ritmo infinitamente lento, o processo cumulativo de transformação da significação da vida em relação a um meio infinitesimalmente 'desnaturalizado'. Tudo isso pode legitimamente ser bem definido como a emergência do 'trabalho', em sentido mais forte na história da vida. Com a fabricação de ferramentas, essas primeiras espécies industriosas podem progressivamente suplantar a seleção natural como fator explicativo das mudanças, transformando a Evolução em (pré) História.

Mas, colocada à parte a probabilidade de certa especialização dessas populações, de produtores de indústria lítica, essa definição muito genérica do trabalho não representa em nada a economia viva, os horizontes de valor dessas sociedades de caçadores-colhedores. Por essa razão, considerando 
esse momento que Gordon Childe (1964) tinha nomeado de "revolução neolítica" (por volta de 7.500 a. C.), outros estudiosos foram conduzidos a situar nesse período, com bons motivos, o 'verdadeiro' nascimento do trabalho, dada a significância social, econômica, cultural, que ele ali manifesta: presencia-se a emergência de sociedades de 'produção', sedentarizadas, cuja temporalidade da vida social é organizada e pontuada pelos ritmos da agricultura e da criação de animais. Comportamento prodigiosamente original, conforme Cauvin, 3

(...) a iniciativa agrícola como inauguração de um novo comportamento das comunidades sedentárias face a seu meio natural (...). Espectadoras até então dos ciclos naturais de reprodução do mundo vivo, as sociedades neolíticas se autorizam a ali intervir como produtoras ativas (Cauvin, 1994, [s. p.]).

Nesse caso, a dificuldade não é de atribuição, como para o primeiro nascimento, mas de interpretação. Relembremos que a tese de Cauvin se construiu frontalmente contra toda explicação dessa revolução pelas pressões de tipo ecológico (climático, alimentar, demográfico...). Sua tese, que não estamos aptos a discutir, dá a prioridade nessa emergência à 'revolução de símbolos' em detrimento da revolução produtiva. Não é a miséria, engendrada nas e pelas relações de produção, que produziria a alienação religiosa, como os sucessores de Marx puderam defendê-la: aplicar esse modelo à pré-história equivaleria a "tomar o efeito pela causa" (Cauvin, 1994, p. 276).

Um acontecimento se produziu, e ele é de natureza psíquica. Nós o definimos como uma nova fissura no seio do imaginário humano entre um alto' e um 'baixo', entre uma ordem da força divina personificada e dominadora e aquela de uma humanidade cotidiana cujo esforço interior na direção dessa perfeição que o transcende pode ser simbolizado pelos braços elevados daqueles que oram [des orants] (Cauvin, 1994, p. 98).

Esse seria aquele estado inicial de angústia, de miséria psíquica, simbolizado pelos que oram, e seria engendrado, por seus efeitos dinâmicos, por esse "desejo de mudar", por essa ambição acelerada de "progresso", por esse "desejo apaixonado de romper os velhos equilíbrios" (Cauvin, 1994, p. 276), de novas relações, produtivas, industriosas com o meio do qual nós somos hoje os herdeiros.

Tese, sem dúvida, aberta a debates, mas cujo ponto forte é, para nós, confrontada aos múltiplos nascimentos do trabalho. Daí o peso essencial dado a 'essa' definição e a 'essa emergência neolítica do trabalho' na inteligibilidade da história humana: 
Um dos propósitos deste livro será mostrar que é bem na revolução neolítica que se enraíza o estado presente da espécie humana, não somente no domínio da exploração do meio, como se acabou de sugerir, mas em sua própria cultura e em suas estruturas mentais (Cauvin, 1994, p. 13).

De fato, é bem essa emergência do trabalho, quaisquer que sejam suas causas, que vai impulsionar o homo sapiens adiante na história.

Entretanto, em nossa consciência comum, o sintagma 'trabalho' sem explicitamente apagar as duas definições precedentes, a primeira, genérica quanto à espécie humana; a segunda, demiúrgica quanto à sua vida psíquica e social, evoca hoje, mais espontânea e massivamente, o que se pode chamar 'o trabalho stricto sensu': prestação remunerada em uma sociedade mercantil e de direito. Em parte de maneira errônea, porque a humanidade não esquece nada, nossa cultura moderna tem tendência a limitar o trabalho ao que foi desenhado e circunscrito pela Revolução Industrial e pelo assalariamento: a porção de tempo trocada por remuneração. É precisamente isso que permite distinguir 'o trabalho' do 'fora do trabalho' (do 'lazer') ou do 'não trabalho' (desemprego), a esfera socioprofissional e a do privado. É em torno dessa troca amplamente desigual, desde o início imposta, que vão se organizar as classes sociais, os movimentos sociais, a experiência da exploração. A partir do século XIX, as lutas e as contradições sociais, a estruturação das relações de forças políticas vão amplamente se desenvolver em torno dessa noção mercantil do trabalho.

Esse 'trabalho' é, portanto, inicialmente, um tempo, mas ele traz consigo estigmas sociais profundamente marcados. Não é sem razão que se abre com Marx um debate fecundo, notadamente sobre a noção de 'trabalho produtivo' ou sobre a noção de 'ser genérico', remetendo à ideia de homem 'fabricador de ferramentas', o que nós definimos como 'o primeiro nascimento do trabalho'; "movimento do trabalho útil em geral, abstração feita de toda marca particular que lhe pode imprimir uma ou outra fase do progresso econômico da sociedade" (Marx, 1983); ou então como uma noção historicamente muito mais delimitada, como segmento de trabalho, mais ou menos produtor da mais-valia, tanto quanto o tempo de "sobretrabalho" possa ser, nesse segmento, mais ou menos aumentado. 4

Não é por acaso que o trabalho, como 'tempo de vida vendido', tenha acarretado como consequência que a questão do tempo de duração do trabalho tenha sido e seja, desde o século XIX e, sob diversos aspectos, até hoje, uma questão socialmente crucial.

Sem dúvida, fala-se hoje de 'trabalho doméstico', de 'trabalho militante', de 'trabalho sobre si', mas a abordagem mercantil do trabalho veio progressivamente sufocar, mais ou menos, as outras definições dele. 
Sociedades neolíticas de produção são substituídas, pouco a pouco, por sociedades (arc-boutées) apoiadas sobre a produtividade, nas quais, com o desenvolvimento do capitalismo, a utilização do trabalho mercantil, do trabalho juridicamente 'subordinado', aparece como o centro.

Cada um desses 'nascimentos' pode ser definido como tal muito legitimamente. Mas ao mesmo tempo, como o precisava Cauvin, “a interrogação sobre o passado, na pré-história, exatamente como em outros períodos, não é neutra". Tanto a posição consensual evocada anteriormente, "acolher tanto declinações eruditas quanto ordinárias de situações qualificadas de trabalho" (Cauvin, 1994, p. 13), pode parecer justa quanto ela pode ser mal aceita na comunidade científica, porque subsiste a ideia de que o trabalho deve ser definível, caso contrário, posições conceituais, institucionais, filosóficas, políticas não poderiam mais ser mantidas.

\section{Segundo impasse}

Podemos nomear o segundo impasse como o da impossível simplificação do trabalho. Impossibilidade somente parcial, certamente. Pois o fracasso dessa ambição para desatar as opacidades do trabalho vem de longe e nos parece perfeitamente representativo das dimensões invisíveis que o trabalho possui.

A história dessa impossível simplificação começa mais ou menos no século XVII, com a ideia de uma filosofia da natureza. Se é possível conhecer as leis que regem a transmissão das figuras e dos movimentos dos corpos, pode tornar-se mestre e possuidor desta natureza, desde que se consiga reduzir as combinações complexas de movimentos a encadeamentos simples e evidentes.

Mas essa ambição somente alçança voo sobre bases tecnoeconômicas com os autores britânicos, sobretudo os escoceses ${ }^{5}$ da segunda metade do século XVIII: “A perfeição, relativa às manufaturas, consiste em poder viver sem o espírito, de maneira que, sem requerer a mente, o ateliê possa ser considerado como uma máquina cujas partes são os homens" (Ferguson, 2000, s. p.). Ferguson citado aqui (Essai sur l'histoire de la société civile, de 1767, traduzido em francês em 1783), Mandeville e Hume estão convencidos de que as operações industriosas podem ser simplificadas nas modernas manufaturas, e que aí está a causa primeira do poder econômico do Reino Unido, na Europa.

Adam Smith, identificando a divisão do trabalho como a causa primeira da riqueza das nações, imputa sua fecundidade a três elementos. O primeiro se apoia sobre esta ambição, mas não sem ambiguidade: a divisão do trabalho acresce a habilidade de cada operário individualmente; reduzindo sua tarefa “a alguma operação muito simples, e fazendo desta operação a única 
ocupação de sua vida"; ela "lhe faz adquirir necessariamente uma enorme destreza" (Smith, 1991, p. 74-75). Destreza sem dúvida, mas cujo inverso negativo - simplificar o trabalho, por conseguinte, o trabalhador - é amplamente retomado no inquieto Livro V (Smith, 1991) por exemplo:

Um homem que passa toda sua vida cumprindo um pequeno número de operações simples, cujos efeitos são talvez sempre os mesmos ou muito próximos dos mesmos, não tem condições para desenvolver sua inteligência nem para exercitar sua imaginação a buscar expedientes para descartar dificuldades que nunca se apresentam; ele se torna, então, tão estúpido e tão ignorante quanto seja possível a uma criatura humana assim tornar-se (Smith, 1991, p. 406).

A dimensão positiva da 'destreza', matriz de resistência a esta desconstrução humana, foi magnificamente desenvolvida pelos trabalhos de Edward Palmer Thompson (1987) sobre a classe operária inglesa. Mas se desenvolve, no campo cultural, a ideia de que a manufatura, ao especializar os homens em operações manuais simples, apropria-se das fontes criativas do trabalho humano.

Ora, menos de um século mais tarde sem falar do Sublime, de Denis Poulot (1870), os tão bonitos capítulos XIII a XV do Livro I de O capital, nos quais, com razão, Marx escreve: a manufatura "deforma o trabalhador, ela faz dele algo monstruoso, ativando o desenvolvimento artificial de sua destreza do detalhe, sacrificando um mundo pleno de disposições e de instintos produtores" (Marx, 1976, p. 49).

Mas o lado positivo da destreza, esta resistência do ofício evocada por Thompson, mantém uma restrição muito forte à pressuposição de simplificação, à ambição de penetrar os segredos do trabalho:

A habilidade do ofício permanece a base da manufatura, ao passo que seu mecanismo coletivo não possui um corpo material independente dos próprios operários, o capital deve lutar sem cessar contra a insubordinação destes (Marx, 1976, p. 56).

Essa contradição a resolver é, para Marx, o verdadeiro itinerário a ser enfrentado para tentar explicar a aparição da Revolução Industrial e do maquinismo, e não, por exemplo, o aperfeiçoamento da máquina a vapor, como o sugeria a grande obra de Paul Mantoux (La Révolution Industrielle au XVIIIe Siècle, 1973). O maquinismo, cuja base é a "máquina de operação", é o que permite suprimir "a força de trabalho como princípio regulador da produção social" (Marx, 1976, p. 57). “Desde que o instrumento, saído da mão do homem, é manejado por um mecanismo, a máquina-ferramenta tomou o lugar do simples instrumento. Uma revolução se cumpriu, mesmo que o homem permaneça como o motor" (Marx, 1976, p. 60). 
Sobre essa emancipação fundamental, em relação à virtuosidade humana, poderão ser acrescidos outros poderes, emancipados dos limites biológicos e subjetivos do trabalhador, o motor mecânico, a decomposição científica dos processos e a grande indústria: “criou-se assim uma base técnica adequada e pôde então funcionar sem amarras" (Marx, 1976 p. 69). É por isso que "o trabalho simples tornou-se o pivô da indústria", como o diz ainda Marx, em Misère de la philosophie (Marx, 1972, p. 64) e a força de trabalho pôde cessar sua resistência ao governo do trabalho.

Entretanto, meio século mais tarde, Taylor, familiarizado com os ateliês de produção, constata escandalizado que:

(...) aqueles que têm um conhecimento profundo de diferentes ofícios podem se dar conta da ausência de uniformidade dos métodos segundo os quais são executados os diferentes trabalhos que constituem um ofício. Em lugar de considerar como uma norma um único método de trabalho, emprega-se, de uma maneira corrente, digamos cinquenta ou cem maneiras diferentes de execução de cada elemento do trabalho (Taylor, 1971, p. 61).

Ou seja, a contribuição dessa força de trabalho operária, que a simplificação pela grande indústria deveria ter reduzido a uma total transparência, manifesta uma variabilidade quase anárquica, que desencoraja toda administração um pouco racional. "Em consequência, os diretores mais experientes deixam sem hesitação aos seus operários a responsabilidade da escolha do melhor e mais econômico modo de execução do trabalho" (Taylor, 1971, p. 61).

Esta é uma situação absurda na medida em que "existe sempre um método e uma ferramenta que permitem um trabalho mais rápido e melhor que todos os outros" (Taylor, 1971, p. 32).

A ascensão do regime da Organização Científica do Trabalho (OCT), no século XX, nos Estados Unidos, depois na Europa, com um ponto alto nas indústrias manufatureiras, por volta do fim dos anos 1960, decorre do princípio de que se pode, ao se ir em busca do infinitesimal, ao se decompor radicalmente os gestos e medir os tempos, arrebatar todo mistério do gesto produtivo e fazer passar todo o saber do trabalho para o lado ao qual Diderot chamava, na Enciclopédia (verbete 'Arte'), o 'conhecimento inoperativo', aquele dos engenheiros e técnicos, aquele que pode se abster de toda prática para normalizar exaustivamente a otimização do gesto produtivo.

Certamente, os historiadores do trabalho nos permitem mensurar em que medida a OCT jamais, e longe disso, cobriu todo o campo da produção industrial. Mas se é incontestável que esse movimento concorreu para a redução do trabalho à pura execução e pôde de fato transformar profundamente as estruturas da produção social, multiplicar a produção de riquezas e inscrever-se como um elemento fundamental de inteligibilidade da his- 
tória contemporânea, seus limites, seu revés parcial no fim dos anos 1960, manifestam bem que as fontes da produtividade social precisam sempre ser retomadas. Essa busca da impossível simplificação se apoiou visivelmente sobre um parcial desconhecimento do que é a atividade industriosa humana.

Esse postulado é assumido hoje?

Certamente, em nossos dias, ninguém se diria abertamente taylorista; o governo do trabalho, a gestão dos recursos humanos, propõe-se, ao contrário, a afrouxar a pressão sobre os processos operatórios, conscientes de que é melhor prescrever objetivos do que prescrever uma atividade que jamais se chega a abranger racionalmente. Mas a história continua a tatear, porque se continua a avaliar mal o que não se consegue acercar no trabalho. Certas 'inovações' de gestão, como as práticas de normalização, certificação, não são isentas de retornos velados aos falsos confortos do taylorismo. De fato, a história segue de maneira caótica, crítica, com recaídas, ultrapassando de longe os lugares e os tempos ditos 'de trabalho', porque três elementos continuam a interagir, em um relativo desconhecimento recíproco: [1] a preocupação própria a todo trabalho humano, "sem uma marca particular", teria dito Marx, de normalizar, de racionalizar, de se avaliar, o gênio humano felizmente não retorna ao zero a cada um de seus empreendimentos; [2] a preocupação própria a nossas sociedades contemporâneas, fundadas sobre a mercantilização do trabalho, de gerá-lo, mesmo em parte às cegas, de se dar instrumentos de governo, de medida, de avaliação do que ele pode trazer ao campo da concorrência mercantil; [3] o renascimento permanente daquilo que, na atividade humana, escapará necessariamente a toda codificação seja ela qual for, e a fará aparecer aqui como sempre em parte simplificada.

\section{Terceiro impasse}

O terceiro impasse diz respeito às 'ilusões' da divisão do trabalho. Ainda aí, a formulação é amplamente provocadora: as divisões do trabalho na história são a característica maior para a compreensão dos processos sociais; mal se vê como a análise histórica poderia se dar sem elas. No entanto, como manipular com discernimento esse conceito tão fortemente mobilizado no campo das ciências sociais?

Com a precedente aporia da simplificação, encontrou-se já a divisão do trabalho, como o método para conduzir a essa simplificação. Mas é um conceito de uso mais amplo: fala-se também de divisão sexual, da oposição entre a cidade e o campo, de separação entre trabalhadores manuais e intelectuais; e se retornarmos às categorias da produção, falar-se-á de divisão social e de divisão técnica. Como explicita Marx, na divisão social, cada homem da arte de um ofício específico produz uma mercadoria, o sapateiro 
produz sapatos, o que não é o caso, diretamente, dos trabalhadores tecnicamente divididos da manufatura ou da fábrica (Marx, 1976, cap. XIV, p. 44-45). E se a primeira vantagem da divisão 'técnica', conforme foi visto com Adam Smith, é precisamente a de decompor as sequências operativas, este não é o problema do conceito de divisão social, que se preocupa simplesmente com uma especialização das competências, repartidas em ofícios, para assegurar à cidade seus bens essenciais, sem se preocupar com o modus operandi.

Não há meio, pois, de fazer a história sem algo como um conceito de divisão do trabalho. Mas aí ainda é necessário distinguir o universal - relativo - do histórico. Desde que os homens vivem em comunidade, ou seja, provavelmente desde sempre, há divisão do trabalho, visto que ninguém tem interesse nem está apto a fazer tudo. Entretanto, essa palavra 'trabalho', que recobre divisões tão diferentes, não é ela um tanto quanto equivocada?

A divisão sexual do trabalho é, por um lado, uma evidência. Mas até que ponto? Interrogando-se sobre a antiguidade da divisão sexual das tarefas em relação à questão de um matriarcado pré-histórico, Cauvin, para voltarmos a ele, concluía com uma constatação de ignorância. 6 Alain Dewerpe, em sua excelente pequena Histoire du travail (2001), insiste nessa divisão, para ilustrar a instabilidade das fronteiras, separando tarefas masculinas e femininas, e evoca o estatuto dos peleiros de Bâle, de 1226, que dá o mesmo direito aos dois sexos. Nas comunidades de vilarejos medievais, muitos trabalhos são mistos.

Cidade e campo: certamente uma cristalização considerável se opera a partir da Idade Média. Mas que 'trabalho' é dividido? E as fronteiras são nítidas, as circulações são unilaterais? Trata-se muito mais de relações hierárquicas e econômicas desiguais do que de tipos de atividades produtivas nitidamente distinguíveis. Exemplos não faltam: os empresários de seda lioneses estabeleceram a moagem na Drôme e na Ardèche camponesas, 7 e isso se torna como uma 'nebulosa': como dizia há muito tempo Pierre Leon (1978), falando do século XVIII: “cada região têxtil torna-se uma 'nebulosa' de vilas de tecelões (...) dominadas pelo centro vizinho" ${ }^{8}$ As circulações 9 aconteceram sempre em todos os sentidos; os historiadores 10 observaram bem a importância dos trabalhadores rurais no século XIX, sem falar dos polos industriais avançados, instalados em plena ruralidade, como Le Creusot ou Wesserling na Alsácia. E há também os jardins e poleiros de aves nos recintos das cidades.

Também os historiadores tradicionais da protoindustrialização (Mendels, Medick), e hoje dos territórios e dos distritos (sobretudo na Itália), contribuíram para fragilizar - parcialmente - a oposição entre cidade industrial e regiões campesinas voltadas exclusivamente aos ritmos agrícolas e às técnicas rotineiras. 11

Trabalho manual, trabalho intelectual: quem hoje poderia sustentar que o trabalho 'manual' não mobiliza, por meio do corpo, como suporte de uma 
história pessoal, a síntese de microapreciações, de microescolhas, de microjulgamentos (Wisner, 1992)? E quem, ao frequentar hoje as atividades de serviço, poderia negar que um 'pensamento', uma operação intelectual, não é fecunda, não é eficaz, visto que tal operação faz parte de um corpo para o qual viver em seu meio de trabalho é valor ou saúde?

Quanto à divisão social do trabalho (trabalho entendido aqui como definição de um objetivo de produção de um grupo humano, presidido por uma repartição estabilizada de postos ou empregos a serem ocupados), ela pressupõe haver consenso sobre o uso mais racional de nossas potencialidades produtivas, consenso que jamais foi e não pode ser obtido, ao menos em nossas sociedades históricas. Como dizia o filósofo Georges Canguilhem:

Pode-se mesmo se perguntar se uma sociedade, seja ela qual for, é capaz, ao mesmo tempo, de lucidez na fixação de seus fins e de eficácia na utilização de seus meios. Em todo caso, o fato de que uma das tarefas de toda organização social consiste em esclarecer ela própria sobre seus possíveis fins - à exceção das sociedades arcaicas e das sociedades ditas primitivas onde o fim é dado no rito e na tradição (...) - parece revelar que ela não tem, propriamente falando, finalidade intrínseca (Canguilhem 1966, p. 188).

No fundo, para voltar ao que tinha sido evocado a propósito do 'impasse da simplificação', os limites do que Marx chamava a divisão técnica, ilustrados pela história, sempre atual, da Organização Científica do Trabalho, em seu radicalismo, parecem concentrar os perigos de uma manipulação imprudente desse conceito de divisão do trabalho em todos os diversos campos que acabamos de evocar.

'O trabalho', neste sentido, é o quê? Busca-se decompor o quê? Uma combinação provisória de atos executados por máquinas, autômatos, sequências de procedimentos, e atos mais ou menos complementares dos primeiros, nunca claramente explicitados e perceptíveis, produzidos por inteligências e corpos humanos. Combinações profundamente instáveis, a recompor permanentemente, em função dos investimentos sobre arquiteturas de trabalho, ferramentais técnicos, renovações de produtos (materiais ou imateriais), o todo enraizado em histórias de empresa, de serviços, de oficinas...

Esse trabalho ao se dividir mistura, pois, elementos heterogêneos, sequências maquinais e sequências humanas, escolhas instáveis de repartição. Há sempre uma tentativa de citação das tarefas, mas essas tarefas têm uma história híbrida, tal qual o trabalho, que se pretende dividir, esta é uma noção com um lado obscuro.

Teorizar friamente sobre a divisão do trabalho quer dizer que se tomam como sérias as categorias segundo as quais os homens e as mulheres serão divididos. De um lado, certamente elas correspondem a lugares, status, 
categorias socioprofissionais, grades maiores de classificação para a inteligibilidade da história social. De outro lado, elas nunca correspondem à realidade das atividades e das relações ligadas aos lugares de trabalho. Não se contingencia o pensamento dos homens e das mulheres no trabalho mais do que em outro lugar; não se podem circunscrever os horizontes nem de seus projetos nem das heranças que constroem para si próprios, há sempre uma parte impossível. Canguilhem, citando a frase de Taylor aos operários, "nós não pedimos que vocês pensem", comenta:

Ele ia, de um modo rudimentar e brutal, ao coração do problema. É evidentemente desagradável que o homem não possa se impedir de pensar, frequentemente, sem que lhe peçam, sempre quando lhe é proibido (Canguilhem, 1947, p. 125).

Todas as nossas pesquisas sobre as situações de trabalho manifestam que os organogramas são sempre, na realidade, mais ou menos ultrapassados, transgredidos, recompostos; que ninguém quer, nem pode, trabalhar 'decomposto' e mesmo, e, talvez, sobretudo, em um meio taylorizado no qual a instituição dividida em postos de trabalho é a mais rígida.

Essa realidade, que podemos chamar de antropológica, é a razão maior pela qual toda divisão do trabalho, quer seja ela técnica, social, sexual etc., é sempre instável. Os historiadores insistiram - Alain Dewerpe lembrava, a propósito das oposições entre sexos, entre cidade e campo - que essas oposições são apropriadas e estruturadas em relações de dominação. Mas toda dominação é instável em proporções e segundo temporalidades extremamente variáveis. Todo sujeito, todo grupo humano no trabalho é um centro de vida, uma tentativa de apropriação do meio, e sua vida no trabalho não é uma cerca separada de sua ambição de vida global.

Marx já dizia que o ne sutor ultra crepidam, "sapateiro, não vai além de teu sapato", torna-se 'demência e maledição' desde que a grande indústria, impondo a revolução técnica como lei de variação contínua, “obriga a sociedade, sob pena de morte, a substituir o indivíduo dividido, submetido ao tormento de uma função produtiva integral, pelo indivíduo integral, que saiba enfrentar as exigências mais diversificadas do trabalho" (Marx, 1976, p. 166-167). Profetismo talvez um pouco imprudente, mas que remete bem a essas provocações que descompartimentam todo meio de trabalho, que o desenvolvimento da internet reatualiza, aliás, hoje aos olhos de alguns.

O historiador é certamente sensível às instabilidades, talvez mais do que o sociólogo, porque compreende e vê nas instabilidades as premissas da história que continua a se fazer. No entanto, não é assim que foi manipulado mais frequentemente o conceito de divisão do trabalho na literatura: conceito essencial, mas a manejar 'em tendência'. Ele se torna verdadeiramente ideológico quando ele é pressuposto como entidade muito clara para 
ser dividida, detalhada, imposta por segmentos a outros seres humanos presumidos, decompostos por eles; e é isso que está precisamente sempre em debate, o trabalho.

\section{O invisível do trabalho}

Por que esses três impasses em torno do trabalho?

Porque se vai presumi-lo a partir de uma conceituação que sempre comporta uma parte invisível ou uma penumbra. Crê-se, sem razão, saber de forma clara de que se fala quando, no entanto, todo 'trabalho' comporta uma parte invisível provisória, na espera de uma eventual elucidação, e uma parte irredutivelmente enigmática. Para mais bem mensurar essa dificuldade, é bom fazer 'trabalhar' o conceito de trabalho, friccionando-o a 'objetos' ou, antes, a formas limites ou que nos pareçam assim.

Quando fazemos uma pesquisa na internet sobre o 'trabalho invisível', aparece uma chuva de referências sobre o trabalho das mulheres. Certamente, como o lembra Sylvie Schweitzer, em sua obra, Les femmes ont toujours travaillé (2002) (As mulheres sempre trabalharam), inclusive na esfera mercantil, industrial, o que reforça a tese da instabilidade das fronteiras entre trabalho masculino e feminino (mas também a tese das desigualdades de status). Mas essa característica de invisibilidade nas referências fornecidas remete essencialmente a essas 'formas limites' que são as tarefas domésticas, o trabalho doméstico. Ora, essa quase identificação do trabalho invisível com o trabalho feminino no lar, ou do trabalho em instituições beneficentes pode conduzir a duas observações.

A primeira é uma orientação profundamente fecunda, na medida em que nos obriga a sair de nossa reflexão que toma o trabalho no stricto sensu, mercantil, como se esse fosse verdadeiramente o único trabalho digno de atenção, único lugar de envolvimento, de uso e de usura de nossas faculdades industriosas. Como se uma diferença de natureza separasse essas duas formas de atividade humana, prestação mercantil ou não mercantil. Outra maneira de dizer: seria esquecer os outros 'nascimentos do trabalho', esquecer as dimensões antropológicas do gênio humano, para se interessar por ele só quando está enquadrado em uma relação mercantil. Ou ainda, esquecer o conteúdo tão diversificado do trabalho dito 'informal', em que se encontram, sobre o planeta inteiro, todas as continuidades entre as formas ditas 'domésticas' e o trabalho 'por contrato'.

A segunda observação é que se perderia o benefício desse alargamento de sentido se isso nos conduzisse a opor um tipo de trabalho invisível, o trabalho doméstico, a outro, que se tornaria completamente visível por sua negociação contratual, seus procedimentos operatórios, seus produtos, seu 
quadro jurídico-econômico. Ao contrário disso, mensurar as continuidades, as circulações, as transferências, em todos os sentidos entre o informal, o doméstico e as formas mercantis de contrato, é contribuir para redescobrir a parte invisível, enigmática de 'toda' a atividade industriosa, e a impossibilidade de circunscrever claramente os recursos, os atos, os espaços onde se desdobram os corpos e as almas humanas em 'todo' o trabalho, até mesmo o trabalho mercantil.

Assim, restituir à atividade doméstica a condição de 'trabalho' é reequilibrar a nossa visão da vida social e familiar, e também aprofundar a abordagem do trabalho 'em geral', fazendo-nos refletir sobre o que é, então 'invisível' nesse trabalho e, a partir daí, em todo o trabalho. 12

Poderíamos sintetizar essa ideia do trabalho como um misto de visível e de invisível, citando a introdução de nosso colega ergonomista François Daniellou, em uma coletânea, por ele organizada e publicada em 1996, L'ergonomie en quête de ses principes:

Em suas atividades, os homens ou as mulheres tecem no trabalho. Em relação à trama, os fios os religam a um processo técnico, a propriedades da matéria, das ferramentas ou dos clientes, às políticas econômicas - elaboradas eventualmente em um outro continente -, às regras formais, ao controle de outras pessoas... Em relação à cadeia, aqui religados à sua própria história, a seu corpo que aprende e que envelhece; a uma multidão de experiências de trabalho e de vida; a muitos grupos sociais que lhes ofertaram saberes, valores, regras com os quais eles produzem dia após dia; aos parentes também, fontes de energia e de preocupações; aos projetos, desejos, angústias, sonhos (Daniellou, 1996, p. 1, grifos do autor).

Poderíamos aproximar esta oposição da 'trama', o 'visível' do trabalho, e da 'cadeia', o menos visível ou o invisível do trabalho, à capa do livro da mesma obra, cuja ilustração é o cartaz de uma exposição sobre os primeiros camponeses da França mediterrânea. O perfeitamente visível do trabalho está em primeiro plano, é um machado, do neolítico mediterrâneo sem dúvida. No segundo plano está o equivalente à 'cadeia', é uma mão que vai empunhar o machado, mas é uma mão um pouco fantasmagórica, mal esboçada pelas pontas das falanges e pelas protuberâncias da palma. Do objeto técnico - aqui o machado bem conservado -, do quadro objetivado, da prescrição, dos procedimentos escritos, se poderá inferir muitas coisas do trabalho humano, mas nada além do que essa mão esboçada sugere.

E não é por acaso que nos apoiamos em um ergonomista para afirmar essa dimensão de invisibilidade do trabalho. Porque, se mensurarmos a que ponto os historiadores são sensíveis às múltiplas declinações culturais, mentais do ato de trabalho, constatamos que eles quase nunca assimilam os questionamentos do ergonomista (sendo o contrário verdadeiro). 
Isso não quer dizer que a ergonomia seja o alfa e o ômega de uma abordagem 'sensata' do trabalho. Ao contrário, podemos ser persuadidos de alguns de seus limites (desenvolvemos, aliás, uma abordagem ergológica que procura emancipar-se dela). A ergonomia é múltipla, mas, por vezes limitada, pois ela não se apropria sempre dos desafios que fez emergir. Mas sem a aprendizagem do olhar sobre o trabalho para a qual instrui a ergonomia, não há muitas chances de mensurar a importância de uma assunção das dimensões invisíveis ou 'em penumbra' do trabalho. O que o ergonomista denomina de 'crônica da atividade' revela a verdadeira densidade da atividade industriosa: esta jamais é simples, jamais é puro encadeamento de normas, de procedimentos, pensados anteriormente e sem a pessoa que vai trabalhar, porque isso é simplesmente impossível e ao mesmo tempo muito difícil de ser vivido.

Uma atividade de trabalho é sempre o lugar, mais ou menos infinitesimalmente, de reapreciação, de julgamentos sobre os procedimentos, os quadros, os objetos do trabalho, e por aí não cessa de ligar um vaivém entre o micro do trabalho e o macro da vida social cristalizada, incorporada nessas normas. Vaivém que não deixa incólume nenhum dos dois níveis. O que quer dizer que a história da vida econômica, política, social, não pode ser escrita sem um olhar sobre esses múltiplos vaivéns.

Evocava-se anteriormente, a propósito da impossível simplificação do trabalho, a afirmação de Taylor, segundo a qual, nas desordens dos modos operatórios dos operários, impunha-se instituir, enfim, one best way. Ora, o fracasso parcial, que precisou de muito tempo para ser revelado em pleno brilho da OCT, vale para nós como um raciocínio a fortiori: mesmo o trabalho sendo muito enquadrado, permanecem quantidades de variabilidades; as normas do one best way deixam ainda em todos os lugares, mesmo se quase inaparentes, os 'furos das normas', os quais são reenviados aos indivíduos e aos grupos para serem geridos. Esses 'furos das normas', que os ergonomistas têm colocado justamente em evidência, engajam reconfigurações de maneiras de fazer, dos laços coletivos mais ou menos intensos, das aprendizagens, das redes de transmissão de saber fazer, dos valores do uso de si, da saúde no trabalho e, finalmente, reinterrogam - construindo ou destruindo - o que significa viver em conjunto. É, portanto, toda vida social que é surdamente recolocada em questão na oficina, no serviço, no canteiro de obra, para ser (re)disseminada pelos milhares de canais de sociabilidade com os outros espaços da vida social.

Quando se deixa de abordar o trabalho como unidade microscópica, mensura-se melhor como, 'na penumbra', todo trabalho é - mais ou menos - uma provocação para se fazer uso de si por si mesmo, para pensar mesmo quando não se é solicitado, como dizia Canguilhem e, portanto, para construir mesmo que confusamente os esboços de um mundo mais ou menos comum. 
A partir disso, pode-se, sem dúvida, caracterizar toda atividade humana (é aí a tomada de posição ergológica) como um nó de debates entre normas antecedentes e tentativas de 'renormalização' na relação com o meio. Debates frequentemente invisíveis, sustentados em primeiro lugar sobre as normas operatórias, mas sem descontinuidade com as normas de vida que todo meio histórico veicula como misto de valores consensuais e valores contraditórios. O que chamamos de 'o trabalho' e, mais particularmente, de trabalho stricto sensu é uma forma tardia, mas hoje complexa, ricamente crítica, desta atividade genérica.

No trabalho mercantil, as normas antecedentes estão mais próximas do trabalho como prescrições, procedimentos, constrangimentos, relações de autoridade, de poder, mas também os saberes científicos, técnicos, as regras jurídicas, as experiências capitalizadas, tudo o que antecipe a atividade futura de trabalho, antes mesmo que a pessoa tenha começado a agir. As 'renormalizações' são as múltiplas gestões de variabilidades, de furos das normas, de tessitura de redes humanas, de canais de transmissão que toda situação de trabalho requeira, sem, no entanto, jamais antecipar o que elas serão, na medida em que essas renormalizações são portadas por seres e grupos humanos sempre singulares, em situações de trabalho, elas mesmas, também sempre singulares.

Falamos do filósofo Canguilhem, e é por ideias semelhantes que o economista Henri Bartoli propunha repensar sua própria disciplina, como 'serviço da vida', afastando-se da fabricação de modelos homogeneizantes, submetida ao equilíbrio das situações e dos cálculos dos agentes:

Viver, já para o animal e a fortiori para o homem, não é simplesmente vegetar e se conservar, é afrontar os riscos, vencê-los, ser capaz de diversificar normas de escolhas e de decisões. Viver não é suportar as provocações do ambiente, os assaltos do meio sobre sua liberdade, é 'se dimensionar com elas'. (...) Os 'milhões de machados representados', as pinturas rupestres mostram que a humanidade não cessa de ir 'trabalhando' seu mundo. Sem dúvida, nunca os homens estiveram em “equilíbrio com seu meio, e nunca cessarão de se adaptar e de adaptá-lo" (Bartoli, 1996, p. 151).

Quaisquer que sejam as formas inaparentes de trabalho, todas elas são formas renormalizantes do meio humano e têm como ponto de fusão as atividades industriosas; elas contaminam o econômico, o social, o político, os modos de sociabilidade, de ligações ou de 'desligamentos' sociais. Assim, pode-se, por exemplo, compreender por que as grandes concentrações fabris, e não apesar delas, impunham um estrito isolamento dos trabalhadores em seus 'postos de trabalho', produziram, através de milhares de renormalizações industriosas sempre amplamente coletivas, o viver em conjunto 
mais ou menos subversivo, as formas de solidariedades operárias e suburbanas tão características dos anos 1920 a 1970.13 Ao contrário, pode-se compreender por que as 'triturações' das renormalizações coletivas após 1968, abrigadas sob o que se chamava enigmaticamente as "mutações tecnológicas", produziram na vida social formas parciais de 'dessociabilização', mal compensadas por outras formas de reagrupamento que se chama 'a sociedade civil'.

\section{Como tal abordagem ergológica pode contribuir para dar conta dos três impasses evocados}

Sobre os três nascimentos (pelo menos) do trabalho, podemos responder à pergunta anterior: sim, é justo usar o mesmo termo 'trabalho' para essas três emergências tão diferentes; desde que 'trabalho' remeta à significação genérica da atividade industriosa humana, como nó de debates entre normas antecedentes e renormalizações.

Desse ponto de vista, essa definição é justificável mesmo na pré-história. Os especialistas em indústria lítica do paleolítico identificam tanto os métodos de corte estáveis de longas durações, quanto o método levalloisiano, em que, com as variabilidades do sílex e do meio natural local, há a necessidade de repará-lo em cada 'sítio' (Tixier, Inizan e Roche, 1980).

O conteúdo desses debates de normas não é genérico, mas histórico. É cada vez profundamente diferente o que o 'trabalho' - termo comum convoca, satura estes debates. No momento da emergência do ferramental, na ocasião da revolução neolítica, ou com a predominância do trabalho como prestação mercantil, ele nutre, a cada vez, o sentimento, não inteiramente injustificado, de se assistir ao nascimento do trabalho.

Sobre a impossível simplificação: sim, há uma tendência parcial e, até mesmo, massivamente eficaz, à simplificação. Mas, ao microscópio, essa tendência é sempre um pouco ilusória. Nunca terá fim a tentativa de antecipar o que jamais poderá sê-lo. E fazer como se o impossível se tornasse realidade, como o queria a gestão taylorista do trabalho antes de 1968; ou tentar, de outras maneiras, voltar às hipóteses sobre a possível transparência do trabalho, como por vezes, ainda hoje, isso cria contradições sociais que pesam sobre e explicam, em parte, a história que se faz.

Sobre a ilusória divisão do trabalho: sim, as populações humanas se desenvolveram dividindo os papéis e as tarefas entre elas. Divisão que as relações de dominação tentaram, sem cessar, colonizar e estabilizar.

Mas toda situação de trabalho provoca debates de normas individuais e, sobretudo, coletivos. Por meio deles, os protagonistas do trabalho não param de desfazer, de forma não aparente, o impedimento do exercício 'do 
trabalho' deles mesmos, as perspectivas de vida que essas divisões propõem ou impõem. Esses germes de transgressões desestabilizam toda divisão do trabalho, seja ela qual for. Toda divisão do trabalho é sempre um resultado mais ou menos instável, provisório, conflituoso.

\section{Algumas reflexões sobre o trabalho histórico}

Se seguirmos nossa lógica, a história (do trabalho) não pode ser somente uma 'história social' (a das relações entre categorias, classes sociais, a das 'relações profissionais', como se diz hoje, das séries de salários, de contratos...), nem uma história apenas econômica. Se a intromissão ergonômica e, mais amplamente, sem dúvida, a abordagem ergológica, nas configurações atuais do trabalho humano, podem conduzir as empresas a reapreciarem as fontes da produtividade social, seus pontos de crise, a maneira pela qual estabelecem ou desfazem os laços intersubjetivos, como se partilham se retrabalham e se enfraquecem os valores do presente; tudo isso através das 'dramáticas' da atividade industriosa, através da adoção de procedimentos, regulamentos, tecnologias, como, por exemplo, as Novas Tecnologias de Informação e de Comunicação (NTIC) e até a gestão de uma fila de espera ou de atendimento em uma unidade de serviço; então, se esse olhar sobre a parte pouco visível do trabalho transforma nossa compreensão sobre o que gera hoje a crise e urde a próxima a vir, como não se colocar antecipadamente a questão: essas 'dramáticas' entre normas antecedentes e renormalizações não estiveram sempre no âmago das situações passadas de trabalho e não é preciso tentar fazê-las reviver?

Podemos tentar evocar alguns pontos tópicos para exemplificar essas sugestões.

Por exemplo, qual uso é feito em história (das técnicas, do trabalho) dos conceitos de inovação, de rotina, de resistência à mudança? A rotina, dizia André Leroi-Gourhan, como antropólogo mais que como historiador, "quase nunca se pode pensá-la como um ideal. Não se pode desligar a rotina das forças indispensáveis à conservação da personalidade étnica" (Leroi-Gourhan, 1945, p. 457). Aprendemos muito ao lado dos historiadores das técnicas antigas e medievais da Universidade de Provence. Sem dúvida, há uma flecha do tempo: da mó de pedra de triturar ao moinho a pedra dormente e móvel, ao moinho pompeiano 'a sangue', depois ao moinho a vento e a água; do arreio antigo à coleira de espádua, da tração a boi, a asno, a mula à tração a cavalo.

Mas seria um erro traçar uma linearidade a partir do que se pode chamar uma posição de 'exterritorialidade' em relação às dramáticas da atividade industriosa. Assim como hoje as 'inovações' (ou o anúncio delas 
como tal), concebidas por engenheiros, técnicos, podem, por exemplo, no caso da segurança, levar a complicar a tarefa dos operadores, dado que o mundo de microvariáveis locais a gerir, nos prazos e condições impostas, caem em desuso ou se tornam objeto de conflitos, da mesma maneira é impossível designar fora da atividade, independentemente de suas condições 'clínicas' globais, o que é 'progresso técnico'. Para evitar investimentos ineficazes, constroem-se hoje grupos de trabalho por projetos, dispositivos de ergonomia de planejamento. Não haveria, para os historiadores, que se imaginar tais dispositivos para tentar retrospectivamente elucidar a história, no fundo muito obscura, dos meios técnicos humanos?

Uma história das inovações contada só pela 'trama', ignorando a 'cadeia', ou seja, pelo aparente do trabalho, ignorando-se sua herança, é sempre um risco de desalinho em relação à história real. Assim o que fazer com os moinhos industriais de farinhas de Barbegal, perto de Arles, no século II d. C., só retomados depois de vários séculos? Por que a persistência do arado de bois quando a tração a cavalo é conhecida? Por que persistir em ceifar com a foice quando existe a roçadeira? Para a moagem, dentro dos parâmetros, é preciso levar em conta o grau da umidade do grão a moer, sua textura, é o grão naquela pedra (mais ou menos 'aparente', vascular); para a atrelagem (do animal), concorre o conjunto da estrutura de atrelamento que é implicitamente o objeto das arbitragens técnicas dos camponeses: canga, carro, carga, arreio, tração, e também a natureza e o estado das vias de transporte, distância habitual das trocas. 14

O uso persistente da foice não é, demonstra nosso colega Georges Comet, na maior parte dos casos, o efeito de uma 'rotina', mas de um excelente cálculo econômico, no sentido de que é necessário intervir nos debates de normas sobre o uso da palha, o tipo de economia rural (economia familiar de subsistência em que mulheres e crianças são partes integrantes ou grande propriedade de exploração para o mercado), o custo da força de trabalho, considerando as perdas em grão com a roçadeira, natureza do cereal, fragilidade da espiga no caule, época da colheita.

Dir-se-á: mas o gênio dos historiadores já chegou a esses elementos de 'cadeia'! Certamente, se acrescentará que a presença dos ergonomistas e dos ergólogos, cujo reflexo é tentar se instalar no coração da atividade e de seus debates no vaivém do micro ao macro, do local ao global, debates que eles não podem antecipar nem modelar, poderia orientar diretamente os historiadores sobre cada caso estudado. A esses tipos de questionamentos, aos quais, em contrapartida, os 'ergopraticantes' são incapazes de responder, pela impossibilidade de desenhar o conjunto dos horizontes clínicos do momento da história considerada. Tentar, por princípio metodológico, manter aberta a entrada pela 'cadeia', mensurar que o essencial de todo o trabalho esteja talvez na dialética entre trama e cadeia, conduz a reapreciar os conceitos 
de inovação, de rotina, de resistência à mudança. ${ }^{15}$ A classificação de 'rotina' é frequentemente uma maneira de ocultar as escolhas e os valores daqueles a quem se procura impor transformações de economia ou de vida que lhes são desfavoráveis, do ponto de vista de seus recursos, da economia de seu 'si'.

Esse conceito (de rotina) não é certamente um conceito 'proibido', mas a ser manipulado com prudência e respeito aos nossos semelhantes. Veem-se também as implicações para a museografia: pode-se pensar nas críticas feitas anteriormente por Haudricourt e colaboradores (1986) sobre as classificações lineares de arados: como conciliar a existência de um sentido de inovação com a recusa da exterritorialidade no julgamento de valor sobre as escolhas de vida das pessoas e grupos humanos? Nas palavras de Jaffrès:

Assim a percepção do maquinismo agrícola depende inteiramente da significação social que ele engendra: na França rural do século XIX, a mecanização é sinônimo da perda de empregos e meios de vida; no Oeste dos Estados Unidos, a mecanização é sinônimo de conquistas de novas terras e da solução para falta crônica de força de trabalho (Jaffrès, 2000, p. 46).

No campo das relações sociais, o que se torna objeto das 'transações', dos conflitos, dos compromissos entre os diferentes parceiros, diz respeito a um objeto no fundo obscuro, que é a atividade de trabalho (as teorias do contrato incompleto, depois a teoria das convenções tocaram essa questão sem ir até o fim).

Por exemplo, em relação ao fenômeno chamado 'paternalismo' -, que nós próprios estudamos um pouco no caso da indústria alsaciana, mais particularmente mulhousiana (região de Mulhouse, Alsácia, na época de sua idade de ouro, fim do século XVIII e sete primeiras décadas do século XIX, com a oportunidade de trocar ideias sobre este tema com historiadores das ciências (Doru Todériciu) e historiadores da industrialização (Michel Hau) -, cabe perguntar: a interpretação dessa 'filantropia patronal', como se dizia na época, não está minada por uma espécie de dilema? Se o paternalismo é uma ferramenta geral de dominação capitalista, então por que sua precocidade, suas formas particulares em Mulhouse e seu quase desaparecimento em certos lugares? Inversamente, se ele está ligado a especificidades confessionais ou culturais particulares em Mulhouse, por que existe também em outros lugares?

Sem dúvida, uma e outra explicação têm certa pertinência. Mas não é preciso introduzir, 'em tendência', as dimensões invisíveis do trabalho, os efeitos em 'cadeia', no sentido de François Daniellou, em parte específicas e prescritas pelas ambições mercantis da indústria mulhousiana para compreender por que é nessa área geográfica que germinaram as primeiras grandes 
realizações dessa 'filantropia'? Ora, estes desafios específicos não são difíceis de identificar, repousam em primeiro lugar sobre a qualidade dos produtos da impressão sobre tecidos, qualidade que se remete em seguida a outros segmentos onde a indústria mulhousiana deveria exercer uma espécie de liderança sobre o continente, o têxtil em geral, a construção mecânica, a indústria química.

Como criar um meio favorável para envolver e transmitir o que é necessário à acumulação de lucros? Criação que nenhum procedimento anterior pode codificar, pois no investimento operário sobre essa 'arte industrial usineira', há mais qualidade e competência do que em outros. Como afirmava um expert alemão, Robert Jannasch - chamado depois, pela Sociedade Industrial de Mulhouse, para dar conselhos sobre as modalidades para negociar a inserção da sua potência econômica do Alto Reno, no espaço comercial do novo Reich alemão, - como não ver que

o aperfeiçoamento dos produtos tem por base uma cultura superior de gostos, assim como elementos intelectuais atuando em sua produção. O fabricante previdente procurará, pois, prover uma cultura artística a todos os indivíduos participantes da produção, ou seja, a toda população operária. É fácil, concluía evocando Mulhouse, representar os esforços do tempo e do capital necessários para amalgamar desta maneira os interesses intelectuais e econômicos de uma população com os interesses de uma indústria, seja em uma cidade, seja em uma província (Jannasch, 1873, p. 132).

As cidades operárias de Mulhouse não teriam alguma coisa a ver com essa tentativa de 'amalgamar' esses dois tipos de interesses entre a população? Será, por outro lado, muito desproporcional e desigualmente beneficiária desse amalgama, visto que os interesses da população operária e os dos industriais, estão mais naturalmente em conflito do que em consenso?

Poderíamos mencionar um debate, a propósito sempre aberto, sobre a ideia de 'produção em massa'. Há algumas décadas, dois pesquisadores americanos, Sabel e Zeitlin, defendiam a ideia de que dois 'paradigmas', não distinguíveis por critérios unicamente econômicos ou técnicos, abriam-se, simultaneamente, a partir da segunda metade do século XVIII: um se organizando em torno de uma produção de massa, padronizada; o outro em torno de uma produção 'flexível', servindo de pano de fundo à variedade de produtos, à habilidade profissional, à inovação técnica permanente, apoiado em redes territoriais, mais precisamente municipais. 16

Sem dúvida há verdade nisso. Mas se o trabalho é sempre (mais ou menos) combinação de trama e cadeia, debate entre normas antecedentes, mais ou menos visíveis, acumuladas, passíveis de ensinar, prescritíveis, codificáveis e de renormalizações, sempre mais ou menos ressingularizantes, poder-se-ia 
dizer que nunca houve, stricto sensu, produção 'em' massa; o homogêneo, o padrão não escapa jamais às renormalizações cotidianas das quais falamos, mesmo no regime taylorista. Entre esses dois paradigmas mencionados, há muito mais, uma diferença de grau, que pode ser mais importante do que uma diferença de natureza (de 'paradigma' no sentido kuhniano).

Então, certamente, a produção de massa existe, mas 'em tendência'. Senão, como compreender a passagem de uma produção de massa à atual economia da variedade? Não se deve supor que os 'operários-massa', os produtores que são também consumidores, exportam progressivamente, a microvariedade criativa do gênio deles, experimentada de maneira mais ou menos consciente na esfera produtiva, para a esfera do consumo (podendo ir até da 'bricolagem' à 'engenhoca')? Se a indústria de massa é suposta produtora de tipos humanos homogêneos e intercambiáveis em suas práticas e em seus gostos, então a emergência da economia da variedade torna-se obscura. Se, ao contrário, toda situação de trabalho, inclusive aquela desdobrada sob o estandarte da padronização, provoca a atividade industriosa às ressingularizações produtoras sociais, então a sequência histórica oferece menos asperezas.

Poder-se-ia, igualmente, interrogar sobre os fenômenos da aprendizagem, sobre a história das escolas de empresa, às quais, por exemplo, militantes operários, em luta sindical ou política com os dirigentes dessas empresas, puderam estar, entretanto, profundamente ligados: por que isso se dá? Porque os estabelecimentos públicos profissionais podiam aparecer liberados da tutela e das estratégias patronais. Nessas escolas de empresa, o patrimônio 'em penumbra', a produção das regras coletivas, as formas localmente criadas do viver em conjunto, geradas sobre a longa duração, as dramáticas do trabalho tinham chance de se fixar e de se transmitir. 17

No entanto, haveria que, sem dúvida, retrabalhar, diversificar as entidades coletivas das quais os grupos humanos se sentem, explicitamente ou não, partes integrantes, reinterrogar as categorias geográficas e as periodizações históricas, sempre a certa geometria variável, que se criam a partir e em torno do que gera 'em penumbra' a atividade de trabalho.

Para nos contentarmos com um pequeno exemplo, 18 a propósito de um jovem estudante de História do Diploma de Estudos Superiores Especializados (DESS), que, tomando por base sua experiência na participação em "colheitas à antiga", 19 debruçou-se sobre a releitura das categorias descritivas do mundo agrícola: como retrabalhá-las a partir de uma percepção 'ergológica' do trabalho da terra? E seu exemplo, tirado dessa experiência vivida no campo berrichonne, ${ }^{20}$ sugere esse vaivém necessário entre categorias gerais e distanciadas, saídas da dimensão 'trama' da vida social e das categorias urdidas muito mais em torno da 'cadeia', ou seja, construídas através da atividade de trabalho. 
Assim, um dos interlocutores do jovem estudante lhe diz a certo momento:

'É necessário compreender bem que eu estou falando do Boischaut Norte'. Efetivamente, o Boischaut Norte, que corresponde ao Norte do departamento de Indre, é marcado por estruturas agrárias particulares: pequenas propriedades e policulturas (vinha e cereais). Nisso, a região se opõe ao Sul do departamento, que é chamada de a Champagne Berrichonne, marcada pela grande propriedade e pela monocultura cerealista. Por de trás dessas distinções, delineiam-se outros desafios sociais e econômicos, outras relações com o trabalho agrícola, outros valores ligados a esse trabalho (cujo processo é, no entanto, o mesmo), culturas diferentes. O pertencimento a um grupo social determinado é, pois, aqui reivindicado, como uma condição da compreensão dos desafios em torno da atividade de trabalho da qual ele nos fala (Jaffrès, 2000, p. 59).

Se hoje quiséssemos compreender por que e o que a história parcialmente persegue através das contradições, conflitos, experiências de trabalho, teríamos, sem dúvida, que reencontrar esse duplo desafio do trabalho mercantil contemporâneo. A parte da invisibilidade, a parte do impalpável, a parte de debates de normas e de 'dramáticas', que sempre existiram no fazer industrioso humano, adquirem hoje, com o crescimento dos 'serviços', com as novas maneiras de produzir, com os novos meios técnicos, uma dimensão muito crítica. O que é o trabalho, o quanto ele custa, em termos de atividade corporal, mental, social, torna-se cada vez mais um ponto cego da vida coletiva. 21

Com os aspectos econômicos da mundialização, têm tendência a aprofundar-se prodigiosamente as distâncias entre os lugares onde se trabalha, dos lugares onde se governa o trabalho e dos lugares onde se decidem as alocações de recursos sobre o uso ou o não uso do 'trabalho vivo'. Essa combinação entre colocar em crescente 'penumbra' o trabalho e o afastamento das instâncias de decisão estratégica sobre ele, que reforça a globalização e se nutre dela, está prestes a produzir um mal-estar multiforme cuja explicação histórica, hoje, não é possível, em nossa opinião, ignorar.

\section{Conclusão}

Esse ponto de vista sobre as dimensões invisíveis do trabalho pode atenuar a contradição entre a ambição da história como disciplina explicativa e nossa experiência do presente: a ambição legítima do historiador deve ser a de tentar ligar um dado estado de uma configuração histórica ao que estava, em germe, em um certo passado a construir. Deontologia determinista, que 
se opõe à experiência do presente, de que ela é sempre progressão de uma trajetória com horizontes amplamente imprevisíveis.

Ora, o interesse para as dimensões de frágil visibilidade da atividade humana em geral, do trabalho em particular, atrai a atenção sobre esses múltiplos debates que se desenvolvem dialeticamente entre micro e macro, entre local e global. Esses debates mantêm em suspenso a cada momento o futuro que virá, propriamente falando, eles 'fazem história'. Presos entre as pressões das normas, dos patrimônios de longa duração e das 'renormalizações' enraizadas nas solicitações por extrema singularidade e atualidade dos atos a cumprir, esses debates são, em grande parte, não antecipáveis por qualquer que seja o modelo de interpretação científica.

Tentando restituir hipoteticamente esses horizontes de debate que mantêm parcialmente em suspenso o destino de todo momento da história humana, o historiador cumpre um trabalho que não invalida a experiência do presente, em que nada é totalmente determinado, decidido para ninguém.

\section{Notas}

${ }^{1}$ Membro do Instituto Universitário da França (IUF) e professor emérito do Departamento de Ergologia da Université de Provence. Doutor em Letras pela Université de Lyon II. <yves.schwartz@univ-provence.fr>

Correspondência: Département d'Ergologie, Université de Provence, 29, Avenue Robert Schuman, 13621, Aix-en-Provence, Cedex 1, França.

2 Le Centre des Travaux Historiques et Scientifiques teve seu congresso anual em Nancy, em abril de 2002, no qual a primeira versão deste artigo foi apresentada. Ele também foi publicado em L'Homme et la Société, n. 152-153, p. 47-77, 2004/2.

3 Jacques Cauvin (1994), grande especialista do Oriente Médio neolítico, desaparecido em 2001.

4 Sobre essa questão, ver a distinção entre "determinação geral" e "especial" em Berthoud (1974) e em Schwartz (1988), principalmente o § 17.3.

5 Ver, sobretudo, Waszek (1988).

6 Ver Jacques Cauvin, "La question du 'matriarcat préhistorique' et le rôle de la femme dans la Préhistoire", em La Femme dans le Monde Méditerranéen. coll. Travaux de La Maison de l'Orient, 10, Maison de l'Orient: Lyon, 1985.

7 Dois departamentos da federação francesa, ao longo do Rio Rhône, onde havia antigas comunidades de camponeses e artesãos (N. T.) Aproveitamos para mencionar a bela obra de Yves Morel, Les Maîtres du Fil. Histoire du moulinage vivarois du XVIIIe siècle à 
nos jours, 3 v., Mémoires d'Ardèche et Temps Présent, 2002. Sur le rôle de Lyon cf. t. I, p. 109-120.

8 Ver Pierre Leon, Histoire économique et sociale du monde. Tomo 4. Paris: Armand Colin, 1978, sobretudo a Introdução de L. Bergeron, e o capítulo II do tomo 2.

9 Por 'circulações' o autor quer nos fazer entender a simultaneidade de atividades camponesas e artesãs nas comunidades rurais, marcas de divisão do trabalho, mas intrínsecas à manutenção da vida na comunidade (N.T.).

10 Por exemplo, a historiadora Rolande Trempe, autora de vários estudos sobre a organização operária e feminina.

11 Sobre Mendels, ver a introdução de Bergeron, em Histoire économique et sociale, Armand Colin, 1978, e "Protoindustrialization: the first phase of the industrialization process", em Journal of Economic History, 32, 1972, p. 241-261; P. Kriedte, H. Medick, J. Schlumböhm, Industrialization before industrialization, Cambridge-Paris, Cambridge Univ. Press-Editions de la Maison des Sciences de l'Homme, 1981. Ver, igualmente, P. Duby, L'economie rurale et la vie dans les campagnes dans l'Occident médiéval. Édition Flammarion, 1977, 1962, p. 60-78.

12 Essa era a questão de uma doutoranda brasileira em estágio no Departamento de Ergologia de Aix-en-Provence, ao intitular um capítulo de sua tese sobre a avaliação do trabalho de pesquisa científica de "O trabalho invisível" (Alvarez, 2000).

13 Lição que pode ser lida na magistral obra de Ivar Oddone e de seus colaboradores (1981) e também no clássico L'etabli, de Robert Linhart (1978).

14 Ver "Permanences et innovations dans les attelages romains", contribuição de Georges Raepsaet ao Colóquio organizado em Aix en Provence, Le temps de l'innovation (Université de Provence, 2000), do qual utilizamos amplamente os Préactes nesses parágrafos.

15 Ver Nouroudine (2001), sobretudo o capítulo IV.

16 Tínhamos sido recrutados por esse grupo, constituído para ilustrar essa tese, com o objetivo de que nossa análise da indústria mulhousiana representasse tipicamente o segundo paradigma da indústria flexível. Ver Sabel C. e Zeitlin J., "Historical alternatives to mass production: politics, markets and technology in nineteenth century industrialization", Past and Present, n. 108, agosto, 1985; nosso Travail et philosophie, convocations mutuelles, Octarès Éditions, 1992, la e 2a parte: Le paramètre travail et l'explication historique; e Piore M. e Sabel C., Les chemins de la prospérité, de la production de masse à la spécialisation souple. Paris: Hachette, 1989.

17 Ver o que dizem as "Instruções ao sósia" na obra de Ivar Oddone, em Schwartz (1988), § 15.2 .

18 Desenvolvemos anteriormente essa questão da categorização histórica em: “De l'inconfort intelectuel ou: comment penser les activités humaines?", em Le paradigme ergologique ou un métier de philosophe. Tolouse: Octarès Éditions, 2000.

19 Ver Abdallah Nouroudine, Technique et cultures, comment s'approprie-t-on des techniques transférées. Tolouse: Octarès Éditions, 2001, principalmente o capítulo IV. 
20 Le Berry é uma região do centro da França (N.T.).

21 Tivemos a oportunidade de falar de 'ofícios em suspenso' (nas págs. 34 e seguintes da obra citada na nota 18) porque, em um número crescente de atividades sociais, a própria substância das engenhosidades, das competências, dos custos, é tão pouco palpável que ela não é mais reconhecida como 'ofício'. Isso, por exemplo, em oposição ao 'ofício de soldar', progressivamente constituído entre as duas guerras, combina dimensões teóricas codificadas e de longas aprendizagens corporais (ver Anne-Catherine Robert-Hauglustaine, "Les métiers du soudage en France", Le Mouvement Social, n. 193, octobre-décembre, 2000).

* Este artigo foi traduzido, do original francês "La conceptualisation du travail, le visible e l'invisible", por Cristine Vargas Pereira e Roseli Figaro, com revisão técnica de Roseli Figaro e supervisão do autor.

\section{Referências}

ALVAREZ, Denise. A temporalidade, a organização do trabalho e avaliação da produção científica: o caso do Instituto de Física da Universidade Federal do Rio de Janeiro. Tese (Doutorado em Engenharia de Produção) defendida na Universidade Federal do Rio de Janeiro, agosto 2000.

BÁRTOLI, Henri. L'économie, service de la vie. Grenoble: PUG, 1996.

CANGUILHEM, Georges. Milieu et normes de l'homme au travail. Cahiers Internationaux de Sociologie, Paris, v. 3, p. 120-136, 1947. PUF, 1966.

. Le normal et le pathologique. Paris:

BERTHOUD, Alain. Travail productif et productivité du travail chez Marx. Paris: Maspero, 1974.

CAUVIN, Jacques. Naissances des divinités, naissance de l'agriculture. Paris: Centre National de la Recherche Scientifique (CNRS), 1994.
CHILDE, Gordon. La naissance de la civilisation. Tradução de P. H. Gonthier. Genève: Gonthier, 1964.

CONGRÉS ANNUEL DU CENTRE DES TRAVAUX HISTORIQUES ET SCIENTIFIQUES. Nancy, France, 2002

DANIELLOU, François. L'ergonomie en quête de ses principes. Toulouse: Octarès, 1996.

DEWERPE, Alain. Histoire du travail. Paris: PUF, 2001.

FERGUSON, Adam. Essai sur l'histoire de la société civile. PUF, coll. Leviathan, 2000 (Edimbourg, 1767, trad. 1783).

HAUDRICOURT, André-Georges et al. L'homme et la charrue à travers le monde. Lyon: La Manufacture, 1986.

JAFFRÈS, Erwan. Comment écrire l'histoire d'une activité de travail: réflexions à partir de l'exemple de l'histoire de l'activité de travail agricole. Monografia. DESS APST 
Aix en Provence: Université de Provence, Departement d'Ergologie, set. 2000.

JANNASCH, Robert. Bulletin de la Société Industrielle de Mulhouse. [s.l.: s.n.], 1873.

LÉON, Pierre. Histoire économique et sociale du monde. Tomos 4 e 2. Paris: Armand Colin, 1978.

LEROI-GOURHAN, André. Evolution et techniques. v. II, Milieu et Techniques. Paris: Albin Michel, 1945.

LINHART, Robert. L'etabli. Paris: Éditions de Minuit, 1978.

MANTOUX, Paul. La Revolution Industrielle au XVIIIè siècle: essai sur les commencements de la grande industrie moderne en Angleterre. Paris: Génin, 1973.

MARX, Karl. Le capital. Livre I, tome II. Paris: Éditions Sociales, 1976.

La misère de la philosophie. Paris: Éditions Sociales, 1976.

Le capital. Livre I. Chapitre VII. Paris: Éditions Sociales, 1983.

NOUROUDINE, Abdallah. Technique et cultures: comment s'approprie-t-on des techniques transférées. Toulouse: Octarès, 2001.

ODDONE, Ivar et al. Redécouvrir l'expérience ouvrière. Paris: Éditions Sociales, 1981.

POULOT, Denis. Sublime. [s.l.: s.n.], 1870.
ROCHE, Hélène; TIERCELIN, Jean-Jacques. Comptes rendus de l'Academie des Sciences de Paris, 1871, 1977. Série D.

ROCHE, Hélène. Nature, 6 mai 2000.

SCHWARTZ, Yves. Expérience et connaissance du travail. Paris: Messidor, Éditions Sociales, 1988.

SCHWEITZER, Sylvie. Les femmes ont toujours travaillé. Paris: Odile Jacob, 2002.

SEMAW, Sileshi et al. Nature, 23 janvier 1997.

SMITH, Adam. Recherches sur la nature et les causes de la richesse des nations. Livro I. Paris: Garnier Flammarion, 1991. cap. 1.

TAYLOR, Frederick Winslow. La direction scientifique des ateliers. Paris: Dunod, 1971.

TIXIER, Jacques; INIZAN, Marie-Louise; ROCHE, Hélène. Préhistoire de la pierre taillée. Paris: CREP, 1980. v. 1.

THOMPSON, Edward Palmer. A formação da classe operária inglesa. Rio de Janeiro: Paz e Terra, 1987. 3 v.

WASZEK, Norbet. The Scottish enlightment and Hegel's account of 'civil society'. London, Boston: Dordrecht Kluwer, 1988.

WISNER, Alain. L' imposture du travail manuel. CNAM: Paris, 1992. Texto para Fédération de la Métallurgie, CGT. 